\title{
THE ROLE OF FACEBOOK IN THE PROCESS OF ACQUIRING INFORMATION. OWN RESEARCH STUDY
}

\section{Malwina Popiotek}

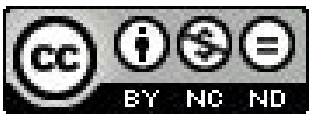

Department of Social Communication and Journalism Institute of Political

Science, University of Opole, Plac Kopernika 11a, Opole, Poland

E-Mail address: malwinapopiolek@gmail.com

\begin{abstract}
This paper focuses on the social network sites (SNSs), especially on Facebook, and their role in people's daily life. It focuses on people who are statistically not at risk of the digital exclusion (young and still educating). Here are presented conclusions of the author's own research focusing on the role of Facebook in daily life of a group of its users. Research was done as an experiment. The purpose of the study was to find out if students, who use Facebook, could stop to do it temporarily. Facebook is here regarded as a main source of various kinds of information, both private and public. In this article the author tries to prove that Facebook is one of the primary channels of information flow.
\end{abstract}

Key words: social network sites, Facebook, information society, social media

\section{INTRODUCTION}

Every day we can observe that social network sites (SNSs), especially Facebook, are an important part of the daily life of most internet users around the world. The number of users of this type of services is growing day by day. According to site zephoria.com in February 2015 there were over 1.39 billion monthly active Facebook users (B) (). Today, we are witnessing the changes generated by the SNSs and these changes strongly affect both the private and the public sphere (e.g. business, advertising, politics etc.).

Statistics show that Facebook remains the most popular social network site. As an incredible source of various information about its users, Facebook is also the subject of many studies. There are publications describing variant dimensions of the SNSs. The study of social media environment deals with representatives of various scientific disciplines: psychologists, sociologists, educators, cultural studies researchers, and so on. The field of new media, especially social media is changing very rapidly, so it raises new research and analysis all the time. In spite of this, it is still difficult to answer the question why Facebook is so popular, and also, why its popularity does not decrease over time, as is the case of other SNSs, but quite the contrary.

This paper focuses on Facebook and on the role it plays for its users. Here we can find the study about the experiment, which was done to explore a few questions connected with the phenomenon of Facebook. 


\section{SOCIAL NETWORK SITES IN SOCIAL SPACE}

The history of social network sites is relatively short. First services of this type like Classmates or Six Degrees, appeared in the middle 90s in USA (Miotk, 2013, pp. 15-17), and the most popular today, Facebook is only 11 years old. Despite this, within this group of social media changes are very dynamic. In the context of information technology eleven years is considered as a very long time.

Initially social media, including social network sites, were treated mostly as form of entertainment, a way to spend some time on the Internet. Some people still perceive them so. But now this approach requires a deep revision because social network sites are today very important for a lot of reasons. Therefore, they are often the subject of research in different disciplines.

\section{WHAT ARE SOCIAL NETWORK SITES}

Researchers define SNSs emphasizing similar things, but there are slight differences. Alessandro Acquisti and Ralph Gross refer to them as online social networks, as they wrote: "at the most basic level, an online social network is an Internet community where individuals interact, often through profiles that (re)present their public persona (and their networks of connections) to others" (Acquisti, Gross, 2006). Andreas Kaplan and Michael Haenlein called them social networking sites and describes them as: "applications that enable users to connect by creating personal information profiles, inviting friends and colleagues to have access to those profiles, and sending e-mails and instant messages between each other. These personal profiles can include any type of information, including photos, video, audio files, and blogs" (Kaplan, Haenlein, 2010).

A more detailed and comprehensive definition is made by researchers Danah Boyd and Nicole B. Ellison. These authors write: "we define social network sites as web-based services that allow individuals to (1) construct a public or semi-public profile within a bounded system, (2) articulate a list of other users with whom they share a connection, and (3) view and traverse their list of connections and those made by others within the system. The nature and nomenclature of these connections may vary from site to site". What is important is that they also noticed that in public discourse the term social network sites is the same as popular as the term social networking sites. Most of the researches emphasize the fact that social network sites can be used to meet new people, gain information, and also keep in touch with other users. But what is interesting, the users of social networking sites such as Facebook, do not indicate that through SNSs they were able to get to know new people. Members usually pay attention to the fact that thanks to Facebook or other SNSs they can refresh some of their old acquaintances, or keep in touch with the people they already knew before. They emphasize the importance of using social networking as the first and main source of all kinds of information ${ }^{22}$.

22 Based on own research (in-depth interviews with Facebook users) done for the PhD dissertation: "Social network sites in the information society"'. 
D. Boyd and N. B. Ellison rightly pointed out that in this type of online service networking is not the key. Authors said: "what makes social network sites unique is not that they allow individuals to meet strangers, but rather that they enable users to articulate and make visible their social network" (Boyd, Ellison, 2006). I strongly agree with this opinion, and that is why I use term 'social network sites' in regard to Facebook. What is more, I also discovered that none of my interviewees made new friends via this service ${ }^{23}$.

To sum up, we can say that social network sites are a group of online services, which are a part of social media, where we can create an account within a broader system, we can build a list of people we know and we can observe and communicate with each other. As an example of Facebook indicates, if we want to participate in this type of activity, we have to agree to the specific terms of contract beforehand. By using the social network sites we can communicate with other users, post our own content, such as photos, videos or comments, and on Facebook we can also express support (by using the button 'I like it!'), declaring participation in events, and promote some content we choose.

\section{WHY DO PEOPLE DECIDE TO USE IT - AN EXAMPLE OF FACEBOOK}

Despite the fact that during the creation of Facebook, there were other similar services, in a few years Facebook has dominated the SNSs market almost completely. Clara Shih explains this fact as the reasons related to specific type of security. In her opinion, people join social network sites to find some valuable information, as well as to share it with other users. The sharing of information, in turn, is related to the confidence and sense of security. The exchange of information and ideas will occur most intensely in an environment where you feel safe. According to C. Shih tools introduced by Facebook, such as authorization by domain email address, mapping real relationships, the ability to adjust the privacy settings, all this meant that service users feel more confident and secure than in other cases of social networking sites. On Facebook you are not anonymous so you are responsible for what you post. Second, according to C. Shih, a distinctive component, which differentiates Facebook from the other social network sites and guaranteeing its success is a policy of involving users, and therefore the possibility of liking something, sending invitations to events, constantly showing newsfeed updates on the activity of your friends (liking, comments, recommended links, etc.) (Shih, 2011, pp. 41-42). Figure 1 shows how Facebook users increasing from the start (2004) till February 2015:

23 The results of this interview are broader in PhD dissertation. 


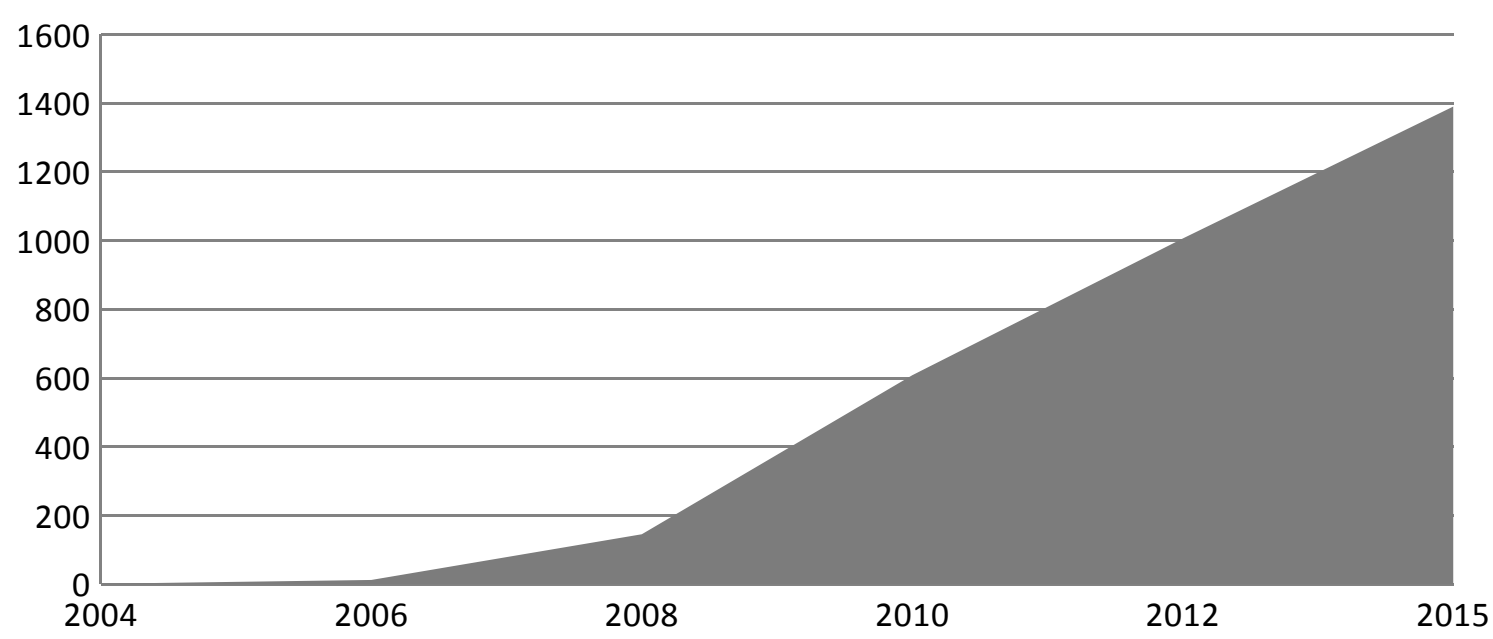

Fig.1. Facebook users in years 2004-2015

Source: Noyes D.(2015), also: Richter F.(2013).

As we can see the trend of Facebook users is still growing. In 2012 the number of users exceeded one billion. In some ways this is the phenomenon. New media is a very variable space. Usually we can observe dynamic changes as regards popularity of each service. Just a few years ago the most popular social network site was not only Facebook, very important was also e.g. MySpace. Now the number of MySpace active users is about $50 \mathrm{mln}$ (A). The same situation we have in Poland, where for a few years there was a great popularity of native SNS - Nasza Klasa (NK). It looked like that till 2012 when the popularity of Facebook prevailed (see: GoogleTrends for 'facebook' and 'NK' compare). These and many other examples show that in the field of social network sites the rank one has gained, does not guarantee long-term success. But Facebook seems to be an exception. It is worth considering why it looks that way.

As we can read in the article $A$ review of Facebook research in the social sciences written by Robert E. Wilson, Samuel D. Gosling and Lindsay T. Graham (2012) there are lot of different motives to use Facebook. Authors analyzed a huge number of publications about Facebook. Based on the analysis, they have identified several reasons for using this SNS described by other researchers. We can group them as follows (Wilson, Gosling, Graham, 2012):

- the external motivations, such as:

- press that encouraged users to engage in Facebook-related behaviour (e.g. birthday reminder, messages, communicator);

- the internal motivations, such as:

- need to keep in touch with friends;

- benefits received from keeping relationships with other people;

- need to relieve boredom;

- needs correlate with self-esteem and loneliness feeling.

I would rather say that what determines Fecebook use mostly is the need to have access to information. This is the basic usage and according to my research, the greatest need for determining the use of Facebook. In the light of the classifi- 
cation above the need to get information would be both, an internal and external motivation. We live in a specific time when information is a fundamental social resource (Toffler, 1997; Shapiro, Varian, 2007, Castells 2000, 2009). We have to have access to various types of information just to lead a normal life, but also we have a strong desire to know more and more, to get the information faster and to set it in order to avoid the feeling of being lost in the world of mass data.

\section{FACEBOOK AS A PRIMARY AND THE MOST IMPORTANT SOURCE OF INFORMATION - OWN RESEARCH STUDY}

The results of the research presented in this paper are the part of broader research done for a PhD dissertation. Here are the results of the experiment which was done in January 2015. In the mentioned dissertation there is an exploration of SNSs from the perspective of their functioning in a networked information society. The study is situated in an interpretative-symbolic paradigm. Qualitative analysis made for the dissertation shown that the need to have access to information for Facebook users is even more important than keeping in touch with others users (friends). Therefore, it was a need for triangulation research methods to find out whether it is right - this method was the experiment. Here is presented the procedure and results of the experiment, which shows the importance of SNSs in the context of access to various kinds of information.

\section{OBJECTIVES AND METHODS}

The purpose of the study was to investigate: what would have happened if a group of young people (students) have to stop using Facebook for some time? The following specific questions were formulated:

- Are Facebook users able to stop using it or not, and why?

- What main advantage of Facebook its users can indicate?

- If Facebook users stop using it what do they lose, and what do they gain?

The study focuses on individuals who are not at risk of digital exclusion. According to statistics, such people are young and still in education (Social diagnosis, 201324). A method of experiment was used, in the research made with the participation of a group of students.

\section{PROCEDURE OF EXPERIMENT}

The experiment was divided into several stages described below. In the first phase, I checked whether students are ready to stop using Facebook for a few days. In the second phase, I investigated if such a decision is easy or difficult for them. The third phase showed their feelings, thoughts and needs when they could not use Facebook and what was the hardest for them during that time. The last

\footnotetext{
24 Social diagnosis is a polish society survey taken periodically on a representative sample.
} 
part refers to interviews with students after the end of experiment with those who took part in experiment, as well as with those who have not decided to stop using Facebook.

\section{First part}

I asked a group of $2^{\text {nd }}$ year students of Journalism and Social Communication if they would be interested to participate in the experiment. In the hall there were about 50 people. I assured them that participation would be voluntary. Initially I did not say what kind of experiment it would be, or what they would have to do.

When only students interested in project (more than 30 people) were left, I began to speak of what it would be about. I explained that to take part in the project, participants would have to delete their Facebook account for a one week. After this term, more than a half of people immediately lost interest and left the room. Over a dozen remained of about 30 people previously.

Second part

A few people were strongly convinced to take part in the experiment from the beginning. There was also a group of a few people that hesitated. I let them think and did not interfere in their decision. Students began to set the strategy of survival. They talked together about how they would deal with this new situation. There were some suggestions, e.g.: 'let's create an Email Box!', 'let's create a forum for our group'! They were discussing and considering the potential possibilities, pros and cons. It took a few minutes. They were afraid of losing some relevant information. The priority for hesitating people was to find new channels for information flow. They wanted to be sure that they would not lose any information, which could be potentially important. After a while several people gave up and left the room. Finally, nine people decided to take part in the experiment, after few minutes one more person came back and joined.

The first thing I wanted them to do after return to their homes was to delete their account on Facebook. When I suggested that, students started to negotiate the conditions. They asked me whether removing their account was necessary. They asked if they could just do not check the Facebook during the time of experiment. They assured me that for the experiment time they will not log into their accounts. I let them decide for themselves which form they choose.

I wanted them to write down notes during a week without Facebook. I asked them to do that always when they felt the need to enter Facebook. I wanted to know how they would deal with this need, and what they would do instead. Also I wanted them to write down their feelings about the situation, and if they decided to stop the experiment, to indicate reasons.

\section{Third part}

Four of participants did diary notes during the week without Facebook as I asked them to. Figure 2, 3 and 4 presents selected fragments from the notes of participants. First fragment below: 


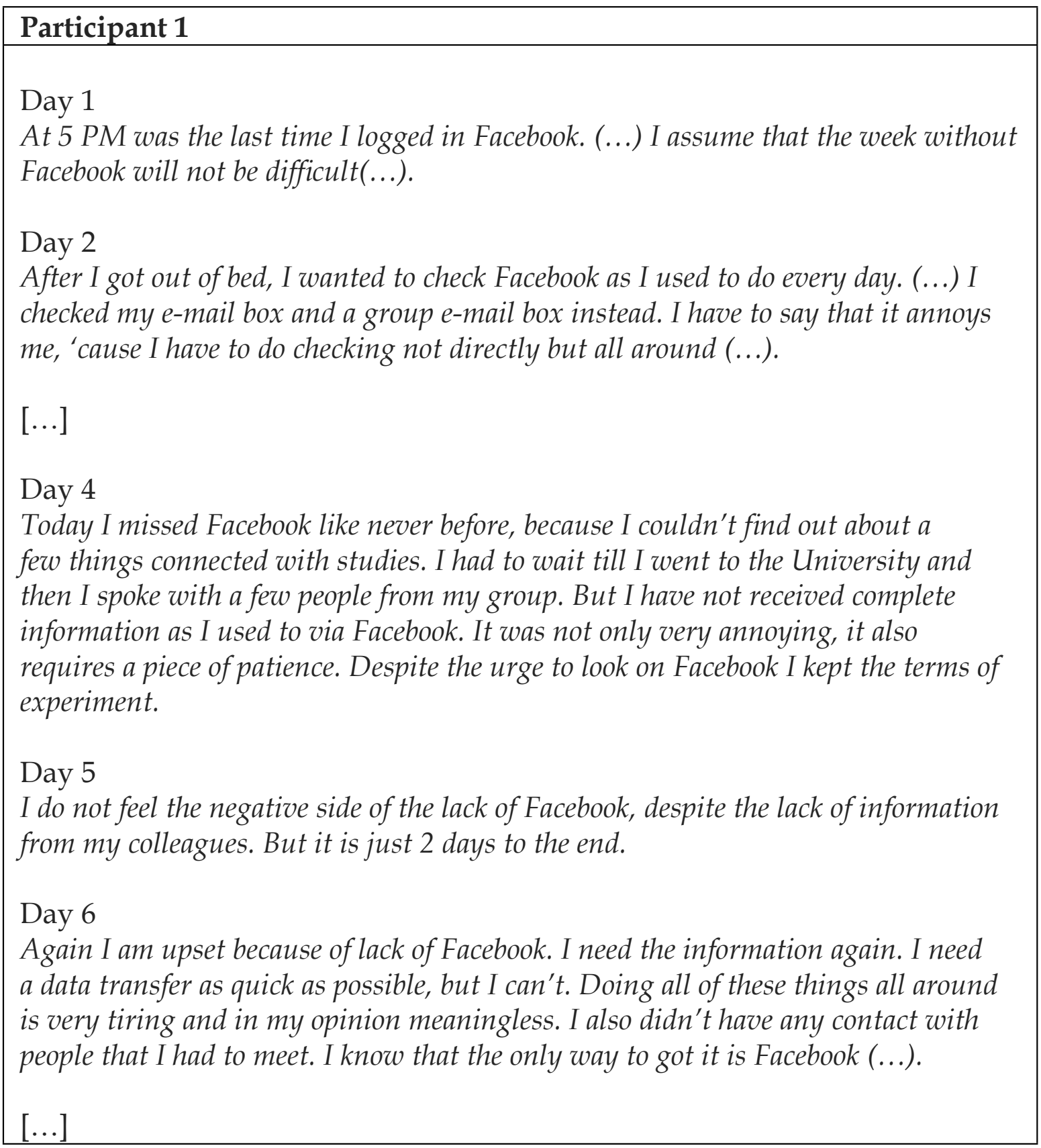

Fig. 2. Participant 1 selected notes.

Source: own research (translation M. Popiołek).

As we can see the most annoying for this participant was difficulties connected with the access to some relevant information. The biggest problem seemed to be with the necessity to search information in different ways. The lack of possibility to check Facebook forced participants to seek for other ways to find out what is going on. The biggest problem appeared when it came out, that information gained in other ways is not satisfactory enough.

It turned out that withstand without Facebook is very difficult, even though at the beginning it seemed quite different. In the notes we can clearly see the sense of anxiety, the fear of missing out (Przybylski, Murayama, DeHaan, Gladwell, 2013). 
We can also notice a tremendous need for being kept informed immediately and directly. Need to use indirect sources makes the participant impatient and upset.

Figure 3 presents another note:

\section{Participant 2 \\ Day 1 \\ (...) The fact that I don't log in on Facebook makes me feel relief and relaxed. \\ Day 2 \\ I asked my friends to send me information via other channels such as mail box or communicator(...). I don't feel upset yet, but asking people about such trivial things made me feel awkward. I'd prefer to have access to information by my own (....). I am afraid of delay or misinformation (...). \\ $[\ldots]$ \\ Day 6 \\ I felt the desire to log in this evening, because I wanted to ask some of my friends for materials to copy for next day's class. A felt embarrassed that I had to ask my friend again, to ask another friend to send me materials. This way I created such a communication chain just for a trivial reason(...). I felt awkward interrupting my friends doing something for me, what I could do by myself. (...)}

Fig. 3. Participant 2 selected notes.

Source: own research (translation M. Popiołek).

In this case we can observe concerns about having to ask others for help in acquiring information. Although at first the participant felt relieved because of stopping using Facebook, eventually it was very uncomfortable. We can see strong belief that you should take care of your access to information by yourself. We can find also signs of concern about delays and misinformation.

\section{Participant 3}

Day 1

(...) I deactivate my Facebook account. Before I did it, I looked through the news of the sites that I liked. I know that the lack of this will be the most irritating for me. I will be forced to review websites regularly to get the news.

Day 2

I have not looked at Facebook, until I came across an interesting web address. It turned out that it leads to Facebook. I was denied access because I did not use FB (...). I was looking for a different address, but without success. It made me realize that the only way to access some of the information is Facebook, unfortunately. It is very irritating. [...]

Fig. 4. Participant 3 selected notes.

Source: own research (translation M. Popiołek). 
This example shows us that Facebook is an aggregator of information. By following some pages we liked, we have a permanent stream of information which is profiled according to our interests and needs. This participant was clearly frustrated and upset because of the necessity to checking each website separately. It also shows that not having a Facebook account could limit our access to some services and in consequence to some information also.

\section{Fourth part}

All who chose to participate, kept the terms till the end of the experiment. Not all of the students deleted their accounts. Most of them just stopped checking it for a week. Both groups were interviewed ${ }^{25}$, those ones who took part in experiment, and also those who resigned after hesitation. I asked them if they had lost something. It turned out that one of participants actually had lost some important information (this person had not arrived at an important meeting, nobody informed her in different way). People in the experimental group lost their feeling of safety with regard to information access, sometimes they lost also some important information. When I asked those, who did not want to take part in experiment,about reasons one person told me: I would really like to take part and delete Facebook account, it is very interesting, so I hesitated. But the risk of losing some information is too big, even just for a week. It is just not worth it. Most of the students accented, that actually they even do not like Facebook, that there are lots of things in it which annoys them. No one has decided to continue not using Facebook much longer than a week.

\section{RESULTS AND CONCLUSIONS}

We are living in the era of information society. It is associated with profound changes in the way of society functioning. In the information society access to information is crucial. As the authors say, in this type of society information is the primary and the most important resource. Access to it can affect or even determines our position (Castells 2000, 2009; Toffler 1997; Rifkin, 2000; Nierenberg, 2011). But not only the access is important, there are also other important issues that determined the quality of access, and in consequence can influence on our situation. We can distinguish few important factors connected with effectiveness of the process of getting information:

- the pace of acquiring information - the faster the better;

- the cost of getting information - the less we have to pay the better, the less effort and time we have to spend the better;

- safety of the information - the more certainty about quality of the information the better.

The experiment shows that Facebook is a very important tool for its users. This is also a very specific tool. It allows people to participate in the process of information flow. It enables us to obtain information quickly, directly, and allows us to reduce effort needed to acquire the kind of information we exactly need. Face-

\footnotetext{
25 Broader information about those interviews in PhD Dissertation.
} 
book users can communicate with others, receive and transmit messages containing the relevant information (both for many people as well as from many people simultaneously).

Answering the specific research questions we can say that for the group of students who took part in experiment the main advantage of Facebook is the fact, that it allows them to participate in the process of information flow. They decide to use it even if they do not feel comfortable about it. For many of them stop using Facebook is an act of a big risk. They can stop use it, but it is difficult, and in their opinion it is connected with inconvenience and risk of losing important information.

Facebook acts as an aggregator of information. There is a wide range of potentially important information available via Facebook. Its users just following what they need, e.g. news sites, sites relating to their interests and also keep following activity of their friends. Thanks to this, they have one tool that provides them with fast and permanent access to different kinds of information, connected with both, the public and private sphere. Thanks to the websites they liked, users have the set of information quickly, directly and looking exactly as they need. All this makes Facebook the primary channel for the information flow

While writing about the growing popularity of social network sites I've used the term socialmediatization of everyday life. At present we can see that the Internet is largely dominated by social networking sites. All the time we can see that a huge number of websites have redirects to SNS. This concerns not just new media. The traditional media also often say: "Visit us on Facebook!". There are even same web portals to which we have privileged access only through an account with a social networking site (Popiołek, 2015).

In the era of the information society use of social network sites can become not only a choice, but almost a necessity. The question is if we are enough aware of threats connected with it? Facebook users think more often about benefits, rarely about consequences. Logging into Facebook means also losing a large part of our privacy, sharing our personal data and getting used to being spied upon. It is hard to tell what will be consequences of that in future, so there is the need for some critical analysis thanks to which we could increase our awareness of the dangers connected with tools such a Facebook that we use readily. We should consider especially if the price we have to pay is really worth it and think whether there is really no other option.

\section{REFERENCES}

Acquisti, A., \& Gross, R. (2006). Imagined communities: Awareness, information sharing and privacy on the Facebook. In: Proceedings of Privacy Enhancing Technologies Workshop, Cambridge, England: Springer, pp. 36-58.

Boyd, D. M., \& Ellison, N. B. (2007). Social network sites: Definition, history, and scholarship. Journal of Computer-Mediated Communication, 13, 210-230.

Castells M., (2000). The Rise of the Network Society, The Information Age: Economy, Society and Culture Vol. I. Cambridge, MA; Oxford, UK: Blackwell

Castells M. (2009). Communication power. Oxford/New York, Oxford University Press

Google Trends indicator for 'Facebook' and 'NK' comparison. Retrieved April 10 $10^{\text {th }}, 2015$ from: www. 
google.com/trends.

Kaplan A. M., Haenlein M. (2010). Users of the world, unite! The challenges and opportunities of Social Media. Business Horizons 53, 59-68.

Miotk A. (2013). Skuteczne social media [Effective social media]. Gliwice: Helion.

Nierenberg B. (2011). Zarządzanie mediami- ujęcie systemowe. [Media management - the system approach]. Kraków: Wyd. UJ.

Noyes D., (2015). The Top 20 Valuable Facebook Statistics - Updated February 2015. Retrieved data from: www.zephoria.com/social-media/top-15-valuable-facebook-statistics/.

Popiołek M, (2015). Serwisy społecznościowe w przestrzeni internetowej - (social)mediatyzacja życia codziennego [Social network sites in the Internet -(sSocial)mediatization of our daily life]. Zeszyty Prasoznawcze, vol. 58, nr 1 (221), s. 60-71.

Rifkin J. (2000). The age of access. New York: J.P. Tarcher/Putnam.

Shapiro C, Varian H. R. (2007). Potega informacji. Strategiczny przewodnik po gospodarce sieciowej [Information Rules: A Strategic Guide to the Network Economy]. Gliwice: Helion.

Shih C. (2012). Era Facebooka [The Facebook Era. Tapping Online Social Networks to Market, Sell, and Innovate.]. Gliwice: Helion.

Social diagnosis 2013, Czapiński J., Panek T. (ed.), Warszawa: Rada Monitoringu Społecznego.

Toffler A., (1997). Trzecia fala [The third wave]. Warszawa: PIW.

Przybylski, A. K., Murayama, K., DeHaan, C. R., \& Gladwell, V. (2013). Motivational, emotional, and behavioral correlates of fear of missing out. Computers in Human Behavior. 29 (4), 1841-1848.

Richter F., (2013). Facebook's Remarkable User Growth. Retrieved data from: www.statista.com/ chart/870/facebooks-user-growth-since-2004.

Robert E. Wilson,Samuel D. Gosling and Lindsay T. Graham (2012). A review of Facebook research in the social sciences. Perspective on Psychological Science, 7 (3), 203-220.

Retrieved April 10, 2015, from www.statisticbrain.com/myspace-statistics/.

Retrieved April 10, 2015, from www.zephoria.com/social-media/top-15-valuable-facebook-statistics/; 